\section{From the Editor's desk}

By Peter Tyrer

\section{Policy and evidence}

It is very rare to come across a health policy that directly follows evidence. There are many reasons for this and perhaps the most compelling is that scientists are not elected by the people but politicians are, or at least should be. They therefore choose to introduce policies that can garner public support and this sometimes takes them a long way away from established evidence. In this issue we report an exception. Improving Access to Psychological Therapies (IAPT) is a UK initiative dating from 2005 that followed directly from evidence from NICE guidelines that the most common mental illnesses, formerly described as the neuroses, could be treated at least as effectively with cognitive-behavioural therapy (CBT) and related time-limited treatments as with antidepressants and anxiolytic medication and, perhaps more relevantly, the cost of this might be recouped from regained employment, with employment advice as a key part of the programme. ${ }^{1,2}$ The results of this initiative, which started at two sites in England, Doncaster and Newham, but has now been implemented in many parts of the UK in the past few years, are beginning to come to fruition. It is perhaps unfortunate that the standard means of evaluating this new initiative, the randomised controlled trial, has not been implemented as part of the evaluation process, but I hope at some point it will be, as even when a programme becomes a statutory one this type of evaluation is possible. ${ }^{3}$ As already indicated in the Highlights section of the Journal, the early results reported here (Mukuria et al, pp. 220-227) are disappointing, with the verdict, 'probably cost-effective', appearing somewhat generous after looking at the data, and this is in keeping with other evidence. ${ }^{1,4}$ In particular, there were no employment gains, but of course economic circumstances have changed dramatically in the years since the initiative was introduced. But these are still early days, and we hope to see much more about who wins and who loses in the programme, including the relative merits of CBT and behavioural activation (Moradveisi et al, pp.204-211), the latter looking to be a strong contender for cost-effectiveness. ${ }^{5}$ But we need more answers soon, the vultures are hovering ${ }^{6}$ and are currently not short of food.

The future of this initiative has worldwide implications. Investing in mental health is never futile; it invariably helps those who suffer from mental disorder but we need to persuade planners and politicians that it pays in other ways too, and this is well illustrated in work carried out in low-income countries where great gains can be achieved ${ }^{7,8}$ with relatively little resources, although much more can be done (Rai et al, pp.195-203), especially for the most severe mental disorders (Farooq, pp. 168169). Most common effective psychological treatments can be given by nurses and psychologists specifically trained for these roles, and there is concern that some of our services in psychiatry might be swallowed up by this generic input. A consequence could be more specialised services such as those described here for bipolar disorder where their resources can be protected (Vieta, pp. 170-171; Kessing et al, pp. 212-219). The overarching message of these findings is a continuous drum roll sounding in the background of all our practice - more research is always needed. Even when policy and evidence seem hunky-dory we must peek behind the curtains and find out exactly what is going on.

\section{Women in psychiatry}

There is a very interesting sentence in Davies' review (pp. 163165) of the implications for psychiatric training following the comprehensive data of Goldacre et al (pp.228-234) on medical careers. 'Women doctors have become the intellectual core of British psychiatry'. I am not exactly sure of 'intellectual core' in this context - presumably the men are spinning idly in the froth on the surface - but it brings up the contentious question, 'are female psychiatrists better than men?' I personally suspect they might be; some time ago we evaluated the assessment of personality and concluded they were superior. ${ }^{9}$ Oscar Wilde, never one to be politically correct, observed, 'women have a wonderful instinct about things. They can discover everything except the obvious'. Clearly not a compliment, but even if it were only partly true, it could help psychiatric skills. Detecting the obvious is a task for any fool; looking beyond the obvious needs special skills ${ }^{10}$ and women may be less easily put off the track than men. If so, the most bothering aspect of Goldacre et al's paper is the reduction in the number of women specialising in psychiatry. It is time for the men to woo.

1 Clark DM. Implementing NICE guidelines for the psychological treatment of depression and anxiety disorders: the IAPT experience. Int Rev Psychiatry 2011; 23: 375-84

2 Layard R. The case for psychological treatment centres. BMJ 2006; 332 $1030-2$.

3 Tyrer $\mathrm{P}$, Morgan J, Van Horn $\mathrm{E}$, Jaykody $\mathrm{M}$, Evans $\mathrm{K}$, Brummell $\mathrm{R}$, et al. Randomised controlled study of close monitoring of vulnerable psychiatric patients. Lancet 1995; 345: 756-9.

4 Hawkes N. Talking therapies: can the centre hold? BMJ 2011; 342: 578.

5 Ekers D, Godfrey C, Gilbody S, Parrott S, Richards DA, Hammond D, et al. Cost utility of behavioural activation delivered by the non-specialist. $\mathrm{Br} J$ Psychiatry 2011; 199: 510-1.

6 Summerfield D, Veale D. Proposals for massive expansion of psychological therapies would be counterproductive across society $\mathrm{Br} J$ Psychiatry 2008; 192: 326-30.

7 Farooq S, Nazar Z, Irfan M, Akhter J, Gul E, Irfan U, et al. Schizophrenia medication adherence in a resource-poor setting: randomised controlled trial of supervised treatment in out-patients for schizophrenia (STOPS). Br J Psychiatry 2011; 199: 467-72.

8 Rahman A, Sikander S, Malik A, Ahmed I, Tomenson B, Creed F. Effective treatment of perinatal depression for women in debt and lacking financial empowerment in a low-income country. Br J Psychiatry 2012; 201: 451-7.

9 Brothwell J, Casey PR, Tyrer P. Who gives the most reliable account of a psychiatric patient's personality? Ir J Psychol Med 1992; 9: 90-3.

10 Bhugra D, Malliaris $Y$, Gupta S. How shrinks think: decision making in psychiatry. Australas Psychiatry 2010; 18: 391-3. 